\title{
Origin and Characteristics of Venturia inaequalis Melanoproteins Active in the Apple Scab Disease
}

\author{
By R. C. HIGNETT, J. H. CARDER AND A. R. W. SMITH* \\ East Malling Research Station, Maidstone, Kent ME $196 \mathrm{BJ}$
}

(Received 27 April 1977)

\section{NTRODUCTION}

Venturia inaequalis, the apple scab organism, has previously been shown to produce biologically-active proteinaceous pigmented metabolites in culture (Hignett \& Kirkham, 1967; Kirkham \& Hignett, I973; Hignett, 1973). The material stimulated the disease when applied as a spray 2 or 3 days after inoculation of test plants; it also showed affinity for ribosomes in vivo and in vitro. Work on its origins, and some physical and chemical characteristics of both intra- and extracellular pigments are described here.

The malt extract medium used in earlier work contained large amounts of polysaccharide which interfered with melanoprotein purification. To avoid this problem a more suitable medium was developed.

\section{METHODS}

Growth of $V$. inaequalis and preparation of pigments. Venturia inaequalis was grown on modified basal medium NC (Kirkham, 1957), in which the hydrolysed casein was replaced by $2.5 \%(\mathrm{w} / \mathrm{v})$ apple twig extract. This was made by refluxing $330 \mathrm{~g}$ powdered Edward VII apple shoots (I-year-old) for $6 \mathrm{~h}$ in $\mathrm{I} \cdot 5 \mathrm{l}$ water. After vacuum filtration the residue was washed with $330 \mathrm{ml}$ water and the washings were pooled and concentrated at $50^{\circ} \mathrm{C}$ under vacuum to $330 \mathrm{ml}$. Particulate material was removed by centrifuging at $15000 \mathrm{~g}$ for 10 min. After adjusting the $\mathrm{pH}$ to $5 \cdot 8,3 \mathrm{vol}$. cold ethanol was added and left overnight at $0^{\circ} \mathrm{C}$. The precipitate was removed by centrifuging as before. The supernatant was evaporated under vacuum at $37^{\circ} \mathrm{C}$ to a syrup, and diluted to $200 \mathrm{ml}$ with water. After extraction with $7 \times 70 \mathrm{ml}$ ether, the aqueous layer of neutral wood extract (NWE) was evaporated under vacuum at $37{ }^{\circ} \mathrm{C}$ to $80 \mathrm{ml}$ (approximately $30 \%$, w/v), readjusted to $\mathrm{pH} 5.8$ and stored over chloroform at $0^{\circ} \mathrm{C}$. The fraction not retained during dialysis $(24 \mathrm{~h})$ (NWED) was used for routine cultures.

Cultures ( $1200 \mathrm{ml}$ ) were grown for $\mathrm{I} 4$ days at $18^{\circ} \mathrm{C}$ in aerated, stirred flasks, and then mycelium was filtered off, washed exhaustively with water and freeze-dried. Culture fluid was reduced in volume by $75 \%$ at $37{ }^{\circ} \mathrm{C}$ under vacuum, followed by dialysis against six changes of water $(72 \mathrm{~h})$ at $5{ }^{\circ} \mathrm{C}$. The pigmented solution was concentrated to $10 \mathrm{mg} \mathrm{ml}^{-1}$ (determined by weighing) and mixed with $\mathrm{I}$ vol. ethanol pre-cooled to - I I ${ }^{\circ} \mathrm{C}$. After $3 \mathrm{~h}$ at $0^{\circ} \mathrm{C}$ the precipitate (N50) was separated by centrifuging, dissolved in $4 \mathrm{M}$-urea and dialysed to remove urea. Two more volumes of cold ethanol were added to the ethanolic supernatant. After $\mathrm{I} 6 \mathrm{~h}$ at $0^{\circ} \mathrm{C}$ the precipitate (N75) was removed, taken up in water and dialysed at $5{ }^{\circ} \mathrm{C}$ against water (six changes) for $72 \mathrm{~h}$. Intracellular pigment was obtained from the freeze-dried mycelium after six extractions with cold ( $\left.-\mathrm{II}^{\circ} \mathrm{C}\right)$ acetone. The extracted mycelium was ground with a small quantity of acid-washed sand and sufficient $0 \cdot 1$ M-sodium phosphate buffer, $\mathrm{pH} 7 \cdot 4$, to form a smooth slurry. This was filtered through cotton-wool and centrifuged for $10 \mathrm{~min}$ at $30000 \mathrm{~g}$. The clear brown supernatant (designated IN) was dialysed against water (four changes) at $5{ }^{\circ} \mathrm{C}$ for $48 \mathrm{~h}$. Particulate material was then filtered out.

Nucleic acid contamination of pigments was removed by electrophoresis in $1 \%(\mathrm{w} / \mathrm{v})$ agarose blocks made up in $\mathrm{O}$ I M-sodium phosphate buffer, $\mathrm{pH} 7 \% 4$. The slow-moving pigment was subsequently recovered by simultaneous elution and dialysis of the macerated agarose: macerated agarose was removed by filtration. The method was tested by separation of ${ }^{32} \mathrm{P}$-labelled fungal nucleic acid from non-radioactive pigment. Nucleic acid was extracted from radioactive mycelium by grinding approximately $5 \mathrm{~g}$ wet wt with $2 \mathrm{~g}$ acidwashed sand in $5 \mathrm{ml} 4 \mathrm{M}-\mathrm{NaCl}$ plus $2 \mathrm{ml} 0.7 \mathrm{M}$-Tris/ $\mathrm{HCl}$ buffer, $\mathrm{pH} 8 \cdot 9$, and $3 \mathrm{ml}$ water. The slurry was filtered and centrifuged at $40000 \mathrm{~g}$ for $15 \mathrm{~min}$. After concentration to $6 \mathrm{ml}, 2 \mathrm{vol}$. cold ethanol were added

* Present address: School of Biological Sciences, Thames Polytechnic, London SEı 8 6PF. 
and left overnight at $0{ }^{\circ} \mathrm{C}$. The precipitate was redissolved in water and dialysed. Insoluble material was removed from the solution which then had an absorption spectrum typical of nucleic acid.

Culture work. Pigment production in cultures was followed by measuring the uptake of $\left[\mathrm{U}-{ }^{14} \mathrm{C}\right] \mathrm{glucose}$ from basal medium augmented with NWED into the non-dialysable fraction of the culture fluid. The $20 \mathrm{ml}$ cultures were grown in $100 \mathrm{ml}$ conical flasks on an orbital shaker $\left(180 \mathrm{rev} . \mathrm{min}^{-1}\right)$ at $18{ }^{\circ} \mathrm{C}$. Similar experiments were done using Io $\%(\mathrm{w} / \mathrm{v})$ malt extract medium (Oxoid). $\left[\mathrm{U}-{ }^{14} \mathrm{C}\right] \mathrm{Glucose}$ was added at $25 \mu \mathrm{Ci}$ per culture or, in some experiments, $\left.{ }^{32} \mathrm{P}\right]$ orthophosphate was added at $100 \mu \mathrm{Ci}$ per culture (both from The Radiochemical Centre, Amersham). Samples ( $2 \mathrm{ml}$ ) were taken every 2 days, freed of fungus and dialysed exhaustively against water at $5{ }^{\circ} \mathrm{C}$. The radioactivity and ultraviolet extinction of the retained material was recorded. Dry weight yields of mycelium and pigment were obtained from duplicate non-radioactive cultures.

Pigment production in stationary liquid culture and on agar plates was observed by visible light absorptiometry $(425 \mathrm{~nm})$. Shaken cultures were also grown within sealed dialysis sacs submerged in culture medium to determine whether low molecular weight compounds were produced, which might be oxidized or polymerized in the extracellular fluid in the absence of the fungus. To test for the presence of oxidase activity, culture fluid from browning cultures was filter-sterilized, added to an equal volume of fresh sterile medium, and then incubated for 12 days at $18^{\circ} \mathrm{C}$; flasks containing a mixture of autoclaved culture fluid and fresh sterile medium were treated similarly. Production of pigment was also tested using basal medium alone, basal medium fortified with whole NWE or the non-dialysable fraction of NWE, or an acid (pH I-5) ether extract of whole NWE. The non-dialysable fraction of NWE contained mainly polyphenols with some polysaccharides and traces of nucleic acid. The ether extract consisted mainly of phenolic compounds. Extracts were added to basal medium in amounts equivalent to $2.5 \%(\mathrm{w} / \mathrm{v}) \mathrm{NWE}$ in the final medium.

Reductive fission. Crushed sodium amalgam [30 $\mathrm{g}, 3 \%(\mathrm{w} / \mathrm{v})$ sodium] was added to $50 \mathrm{mg}$ pigment in $30 \mathrm{ml} \mathrm{I} \%(\mathrm{w} / \mathrm{v})$ caustic soda. The mixture was rapidly stirred under reflux for $2 \mathrm{~h}$ in a nitrogen atmosphere, during which time the dark colour was bleached. The solution was allowed to cool for $15 \mathrm{~min}$, then $6 \mathrm{M}-\mathrm{HCl}$ was carefully added to $\mathrm{pH} \mathrm{I}^{\cdot} 5$. The solution was filtered and continuously extracted with ether for $\mathrm{I} 6 \mathrm{~h}$. The extract was evaporated at $37^{\circ} \mathrm{C}$ under vacuum to approximately $0 \cdot$ I $\mathrm{ml}, \mathrm{I} \mathrm{ml}$ acetone was added and the resultant solution of phenolics was analysed (Farmer \& Morrison, 1960).

Analysis. Thin-layer chromatograms of phenolics were run on silica gel $\mathrm{G}+0 \cdot \mathrm{I} \% \mathrm{~F}_{254}$ (Merck). Plates were developed in chloroform/methanol/acetic acid (83:17:I, by vol.) and after drying at $20{ }^{\circ} \mathrm{C}$ in air, they were developed in the second dimension with chloroform/acetic acid $(9: \mathrm{I}, \mathrm{v} / \mathrm{v})$. Spots were detected under ultraviolet light $(254 \mathrm{~nm})$ and by spraying with diazotized $p$-nitroaniline.

Pigment was further analysed by examining the products of two-stage acid hydrolysis. The first stage was at $100^{\circ} \mathrm{C}$ in $2 \mathrm{M}-\mathrm{HCl}$ for $20 \mathrm{~min}$. The production of dark-coloured material by acid-catalysed condensation reactions was prevented by keeping the concentration of pigment below $10 \mathrm{mg} \mathrm{ml}^{-1}$; under these conditions the yield of melanin was independent of concentration. The precipitated melanin was separated by centrifuging and washed with water to neutrality. The washings were pooled with the acid hydrolysate, and samples were taken for carbohydrate tests. These were done on paper chromatograms developed in butan-I-ol/ acetic acid/water, (4:I:I, by vol.) (BAW). Reagents used included $p$-aminobenzoic acid (Saini, 1966), 2,4dinitrophenylhydrazine (Gray, 1952), and vanillin-perchloric acid (Lambou, 1957). The partial acid hydrolysate was dried on a rotary evaporator at $50^{\circ} \mathrm{C}$ under vacuum, and redissolved in $6 \mathrm{M}-\mathrm{HCl}$ at $2 \mathrm{mg} \mathrm{ml}^{-1}$. The solution was heated to $105^{\circ} \mathrm{C}$ under $\mathrm{CO}_{2}$ in a sealed Pyrex tube for $20 \mathrm{~h}$. The slight precipitate formed was removed, washed twice with water and added to the previous precipitate. The total melanin was dried in vacuo over $\mathrm{P}_{2} \mathrm{O}_{5}$, then at $105^{\circ} \mathrm{C}$ to constant weight. The acid solution, together with the washings from the precipitate, was dried as above after the addition of I vol. water. The evaporation of water was repeated twice, then the residue was dissolved in $10 \%(\mathrm{v} / \mathrm{v})$ propan-2-ol for analysis. Amino acids in the solution were detected with ninhydrin after chromatography on Whatman no. I paper in BAW. Total amino acids were estimated by densitometry of the colour developed with ninhydrin. Samples $(5 \mu \mathrm{l})$ were dried on to strips of chromatography paper alongside reference hydrolysate solutions (Shandon Scientific). The test papers were dipped in acetone containing $0.5 \%$ ninhydrin and $0.5 \%$ pyridine, air dried for I min, then heated to $100{ }^{\circ} \mathrm{C}$ for $3 \mathrm{~min}$. The reference solution spots gave a linear response (up to $5 \times 1 \mathrm{I}^{-3} \mathrm{M}$ ) in terms of integrated areas measured on a Joyce-Loebl Chromoscan, using white light.

Isoelectric focusing of pigment was done on $5 \%(\mathrm{w} / \mathrm{v})$ polyacrylamide gel rods ('Cyanogum' $4 \mathrm{I}, \mathrm{BDH})$ using an acid/water mixture ( $1: 4, \mathrm{v} / \mathrm{v})$ in the gel (Stenman \& Gräsbeck, 1972). The lower and upper electrolytes were $2 \mathrm{M}$-acetic acid and $3 \%$ (v/v) ethanolamine respectively. After development, the gels were scanned in white light using a Joyce-Loebl Chromoscan. Gels were also stained for protein using Coomassie-R (R. A. Lamb, Wembley) made up to $0.25 \%$ (w/v) in methanol/acetic acid/water (20:7:73, by vol.). Gels were destained electrophoretically after being soaked in $2 \mathrm{M}$-acetic acid for $30 \mathrm{~min}$.

Molecular weight studies were done on $\mathrm{I} \cdot 7 \times 42 \mathrm{~cm}$ glass columns packed with Sepharose $2 \mathrm{~B}$ or $6 \mathrm{~B}$, or Sephadex G200, G I00, or G50. Columns were washed exhaustively with water to remove salts, or the detergent used occasionally to clean the gels (Haemasol, I \% (w/v) solution; A. R. Horwell, London). Separations 


\section{Table I. Two-dimensional thin-layer chromatography of the products of reductive fission of pigment}

Separation of the pigment fractions is detailed in Methods. Solvents for chromatography were: solvent $\mathrm{I}$, chloroform/methanol/acetic acid $(83: 17: 1$, by vol.); solvent 2 , chloroform/acetic acid (9: I, by vol.).

\begin{tabular}{|c|c|c|c|c|c|c|}
\hline Spot no. & $R_{F} \mathrm{I}$ & $R_{F} 2$ & $\begin{array}{l}\text { 1-dialys } \\
\text { NWE }\end{array}$ & IN & $\mathrm{N}_{50}$ & $\mathrm{~N}_{75}$ \\
\hline I & 0.40 & 0.10 & - & + & + & + \\
\hline 2 & 0.49 & $0.2 \mathrm{I}$ & + & + & + & + \\
\hline 3 & 0.54 & $0 \cdot 26$ & - & + & - & - \\
\hline 4 & 0.69 & 0.40 & + & + & + & + \\
\hline 5 & $0.7 \mathrm{I}$ & 0.18 & - & + & + & - \\
\hline 6 & 0.73 & 0.34 & - & + & - & - \\
\hline 7 & 0.80 & 0.30 & - & - & + & - \\
\hline 8 & 0.75 & 0.43 & + & + & + & + \\
\hline 9 & $0.8 \mathrm{I}$ & 0.49 & + & + & + & + \\
\hline 10 & 0.78 & 0.55 & + & + & + & + \\
\hline I I & 0.83 & 0.53 & + & - & - & - \\
\hline 12 & 0.85 & 0.60 & + & + & + & + \\
\hline I3 & 0.83 & $0 \cdot 70$ & - & + & + & + \\
\hline
\end{tabular}

were done in water or in salt after equilibration of columns in $8 \mathrm{~mm}-\mathrm{NaCl}$; for the latter, materials were loaded in $4 \mathrm{~mm}-\mathrm{NaCl}$ and eluted with $8 \mathrm{~mm}-\mathrm{NaCl}$. In some experiments, a small column $(0.5 \times 7 \mathrm{~cm})$ was used which could be scanned densitometrically at intervals during elution.

\section{RESULTS AND DISCUSSION}

During I 8 days growth of non-radioactive control cultures, the weight and extinction at $425 \mathrm{~nm}$ of non-dialysable material in the medium increased continuously, as did the dry weight of mycelium (up to $130 \mathrm{mg}$ per $20 \mathrm{ml}$ culture). Duplicate measurements of the latter agreed within $10 \%$. The incorporation of ${ }^{14} \mathrm{C}$ (from labelled glucose in the medium) into the non-dialysable fraction of the culture fluid was similar to that of ${ }^{32} \mathrm{P}$ (added as orthophosphate), and was observed in both cases 3 to 6 days after inoculation, continuing for at least I 8 days. Experiments using malt extract gave similar but less satisfactory results, the growth rate being poor. The phosphorus content of the total non-dialysable fraction was calculated to be $31 \mathrm{~g}$ per $154 \mathrm{~kg}$ (from radioactivity estimations) after electrophoretic purification. ${ }^{14} \mathrm{C}$ was detected in equal proportions in both the melanin and the proteinaceous moieties of the pigment, which indicates its solely intracellular origin. Extracellular pigment was observed only when intracellular pigment was present, suggesting (in conjunction with the isotopic data and the close chemical similarities discussed later) that the former was derived from the latter. Oxidation of putative phenolic compounds exported by the fungus from within dialysis sac cultures was not detected, pigment production being restricted to the sac contents. Non-enzymic reactions could therefore be discounted as a source of melanin.

Extracellular pigment was produced by the fungus only when grown on malt extract, or basal medium fortified with any of the wood extract fractions (total pigment yield was approximately $0.8 \mathrm{mg}$ per $\mathrm{ml}$ culture fluid). Although such pigment was not fully investigated, its ultraviolet absorption spectrum, solubility and behaviour on gel filtration showed it to be very similar to the material produced on NWED medium. Stationary cultures behaved similarly to the stirred, aerated cultures in respect of pigment production. Colonies grown on agar medium developed a brown coloration in the surrounding areas after 6 to 9 days, which corresponds with the time of appearance of pigment in liquid cultures. Thus pigment production is not necessarily associated with mechanically damaged or old autolysed mycelium. Mechanical breakage of whole mycelium by grinding with sand released cytoplasm (containing nucleic acid, lipid, protein etc.) but not pigment. It is concluded 
that the secretion of pigment into the culture fluid by the fungus was not a consequence of adverse physical growth conditions and may therefore occur in the host as indicated by earlier work (Hignett \& Kirkham, 1967).

The phenolic 'fingerprints' displayed by each of the three pigments after chromatography of their reductive fission products showed a common pattern of eight resolvable spots, and various combinations of four more spots. Six of the eight spots were found in reduced wood extract (non-dialysable fraction) together with one other not present in the pigment fingerprints (Table I). Amino-acid analysis revealed a complex mixture in all three pigments. No carbohydrates were detected. Melanin and protein accounted for approximately $42 \%$ and 24 to $29 \%$ respectively of the fungal melanoprotein. Since extra phenolic compounds present in the reduced whole wood extract were not detected in the pigment reduction products, it appears that only a selection of the phenolics available in the medium was utilized. Evidently the high molecular weight wood-extract material can also be metabolized by the fungus with consequent production of pigment.

Electrophoresis on $\mathrm{pH}$-gradient gel of all three pigments gave a single broad band between pH 3.5 and $\mathrm{pH}_{4}{ }^{\circ}$. The use of commercially available ampholytes created artefacts which varied according to the range of ampholyte used. No separation of protein from coloured material was observed. The apparent molecular weight of fungal melanoprotein in dilute aqueous solution was in excess of $25 \times 10^{6}$, the approximate exclusion limit of Sepharose $2 \mathrm{~B}$; but this decreased sharply to less than ${ }^{4} 0^{4}$ on concentration to $20 \mathrm{mg} \mathrm{ml}^{-1}$ or in the presence of $8 \mathrm{~mm}-\mathrm{NaCl}$. This effect was completely reversible, and was also observed with certain dyes.

Thanks are due to A. L. Roberts and Sheila C. Wilson for technical assistance and to Dr D. S. Kirkham for the provision of source cultures.

\section{REFERENCES}

FARMER, V. C. \& Morrison, R. I. (I960). Chemical and infrared studies on phragmites peat and its humic acid. Scientific Proceedings of the Royal Dublin Society: Series A r, 85-104.

Gray, R. A. (1952). Composition of honeydew excreted by pineapple mealybugs. Science II5, I 29-I33.

Hignett, R. C. (I973). The adsorption of silverlabelled fungal pigment by bacterial and apple plant ribosomes. Journal of General Microbiology 79, 95-roI.

HignetT, R. C. \& Kirkham, D. S. (1967). The role of extracellular melanoproteins of Venturia inaequalis in host susceptibility. Journal of General Microbiology 48, 269-275.

KirkhaM, D. S. (1957). Relationships between cultural characters and pathogenicity in Venturia inaequalis and Venturia pirina. Journal of General Microbiology $\mathbf{6 ,}$ 360-373.
Kirkham, D. S. \& Hignett, R. C. (1973). Control of the vertical distribution of apple scab disease on shoots of the apple rootstock MMio9. In Fungal Pathogenicity and the Plant's Response, pp. 5566. Edited by R. J. W. Byrde and C. V. Cutting. London: Academic Press.

Lambou, M. G. (1957). Mobilities of some polyols, sugars, acids and other compounds. Reactions on paper with the Godin reagent. Analytical Chemistry 29, I449-I45I.

SAINI, A.S. (I966). Some technical improvements in the chromatography of sugars. A method of sample desalting and a sensitive staining reagent. Journal of Chromatography 24, 484-486.

Stenman, U.-F. \& GRÄSBECK, R. (I972). Gradients for isoelectric focusing at low $\mathrm{pH}$. Biochimica et biophysica acta 286, 243-25I. 